\title{
Applications of the Carathéodory's Inequality for Driving Point Impedance Functions
}

\author{
Timur Düzenli ${ }^{1 *}$, Bülent Nafi Örnek ${ }^{2}$ \\ $\mathbf{1}^{*}$ Amasya University, Faculty of Engineering and Architecture, Departmant of Electrical and Electronics Engineering, Amasya, Turkey, (ORCID: 0000-0003-0210- \\ $5626)$ \\ timur.duzenli@amasya.edu.tr
}

${ }^{2}$ Amasya University, Faculty of Engineering and Architecture, Departmant of Computer Engineering, Amasya, Turkey, (ORCID: 0000-0001-7109-230X), nafiornek@gmail.com,nafi.ornek@amasya.edu.tr

(International Conference on Design, Research and Development- 15 - 18 Aralık 2021)

(DOI: $10.31590 /$ ejosat.1040073)

\begin{abstract}
ATIF/REFERENCE: Örnek, B. N., Düzenli, T. (2021). Applications of the Carathéodory's Inequality for Driving Point Impedance
\end{abstract} Functions. European Journal of Science and Technology, (32), 326-331.

\begin{abstract}
In this study, the Carathéodory's Inequality, which is a highly popular topic of complex analysis theory, has been applied to electrical engineering to obtain novel driving point impedance functions. In electrical engineering, driving point impedance functions correspond to positive real functions and they are used for representation of the spectral characteristics of a particular circuit. Accordingly, boundary version of the Carathéodory's inequality has been considered here assuming that the driving point empedance function, $Z(s)$ has a fractional function structure with $0<\Re Z(s) \leq A$ for $\Re s \geq 0$ and it is analytic in the right half plane. At the end of the analyses, new driving point impedance functions have been obtained and they have been presented with their spectral characteristics. According to simulation results, it is possible to say that the frequency responses of the obtained generic driving point impedance functions have spiky filter structures where the number of the spikes in the frequency response of these filters depend on a pre- defined parameter, $n$.
\end{abstract}

Keywords: Driving point impedance function, Carathéodory's Inequality, Circuit, Filter.

\section{Süren Nokta Empedans Fonksiyonları için Carathéodory Eşitsizliği’nin Uygulamaları}

Öz

Bu çalışmada, kompleks analiz teorisinde oldukça popular bir konu olan Carathéodory eşitsizliği, yeni süren nokta empedans fonksiyonları elde etmek için elektrik mühendisliğine uygulanmıştır. Elektrik mühendisliğinde süren nokta empedans fonksiyonları, pozitif reel fonksiyonlara karşılık gelmekte ve belli bir devrenin spektral özelliklerini temsil etmek için kullanılmaktadırlar. Buna göre, burada Carathéodory eşitsizliğinin bir sınır versiyonu, kesirli fonksiyon yapıdaki süren nokta empedans fonksiyonu $Z(s)$ için, $Z(s)$ 'nin $0<\Re Z(s) \leq A, \Re s \geq 0$ olmak üzere sağ yarı düzlemde analitik olduğu varsayılarak değerlendirilmiştir. Analizler sonucunda, yeni süren nokta empedans fonksiyonları elde edilmiş ve bu fonksiyonlar spektral özellikleriyle birlikte sunulmuştur. Simülasyon sonuçlarına göre, elde edilen genel süren nokta empedans fonksiyonlarının frekans cevaplarının, sivri geçişli süzgeç yapısına sahip oldukları ve frekans cevabındaki bu sivri geçişlerin sayısının daha önce tanımlanmış olan bir $n$ parametresine bağlı olduğunu söylemek mümkündür.

Anahtar Kelimeler: Süren nokta empedans fonksiyonu, Carathéodory eşitsizliği, Devre, Süzgeç.

\footnotetext{
*Corresponding Author: timur.duzenli@amasya.edu.tr
} 


\section{Introduction}

Investigation of the characteristics of driving point impedance functions (DPIFs) is a hot topic in the electrical engineering literature [1]-[6]. It is well known that DPIFs are actually positive real functions (PRFs) depending on a complex frequency parameter $s$, and they satisfy the conditions of PRFs which are listed as below $[7,8]$ :

$1-) Z(s)$ is analytic and single valued in $\mathfrak{R} s \geq 0$ except possibly for poles on the axis of imaginaries,

2-) $Z(\bar{s})=\overline{Z(s)}$

3-) $\mathfrak{R} Z(s) \geq 0$, in $\mathfrak{R} s \geq 0$

In addition to their use in electric circuits, it is possible to encounter with PRFs in signal processing, in control systems and even in microwave engineering.

Here, we aim to perform boundary analysis of DPIFs. Carathéodory's Inequality is considered here to obtain boundary inequalities for the derivative of DPIFs. Assuming that $Z(s)=$ $\frac{A}{2}+c_{1}(s-1)+c_{2}(s-1)^{2}+\ldots$, a lemma and a theorem are presented. In these lemma and theorem, two inequalities have been obtained for $\left|Z^{\prime}(1)\right|$ and $\left|Z^{\prime}(0)\right|$, respectively. For each obtained inequality, sharpness analyses have been performed and two extremal functions, which are actually corresponding to two distinct DPIFs, have been obtained. The obtained DPIFs have been considered by investigating their frequency characteristics.

We aim to investigate the potential results of application of Carathéodory's inequality to derivative of DPIFs and the analyses presented here are arisen as the natural results of the problem.

The rest of the manuscript is organised as follows: Preliminary considerations are presented in Section 2 and in Section 3, main results are discussed. Finally, in Section 4, conclusions are given.

\section{Preliminary Considerations}

The behaviour of a bounded and analytic function which maps the origin to the origin in the unit disc $U=\{z:|z|<1\}$ is examined in the traditional form of the Schwarz Lemma. Schwarz lemma is highly effective such that it is possible to encounter with this lemma in proofs of many important theorems. Schwarz Lemma is given in the most basic form as follows ([9], p.329):

Suppose that $f(z)$ is analytic in $U$ and $|f(z)|<1$ for $|z|<$ 1. If $f(0)=0$, then $|f(z)| \leq|z|$ for all $z \in U$ and $\left|f^{\prime}(0)\right| \leq 1$. If $\left|f^{\prime}(0)\right|=1$ or $|f(z)|=|z|$ some $z$, then $f(z)=b z,|b|=1$.

Now, Carathéodory's inequality $[10,11,12]$ at right half plane for PRFs will be presented.

Let $Z(s)=\frac{A}{2}+c_{1}(s-1)+c_{2}(s-1)^{2}+\ldots$ be a positive real function with $0<\Re Z(s) \leq A$ for $\mathfrak{R} s \geq 0$.

Consider the function

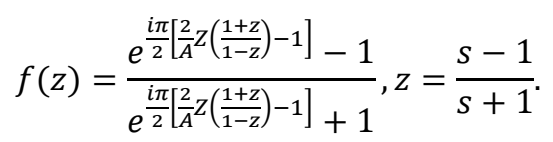

Here, $f(z)$ is an analytic function in $U, f(0)=0$ and $|f(z)|<1$ for $|z|<1$.

Consider the product

$$
B(z)=\prod_{k=1}^{n} \frac{z-z_{k}}{1-\overline{z_{k}} z}
$$

Let

$$
\varphi(z)=\frac{f(z)}{\prod_{k=1}^{n} \frac{z-z_{k}}{1-\overline{z_{k}} z}}, z_{k}=\frac{s_{k}-1}{s_{k}+1}, k=1,2, \ldots, n .
$$

Here, $s_{1}, s_{2}, \ldots, s_{n}$ are points in right half plan and $z_{1}, z_{2}, \ldots, z_{n}$ are zeros of $f(z)$. Also, $\varphi(z)$ is an analytic function in $U, \varphi(0)=0$ and $|\varphi(z)|<1$ for $|z|<1$. So, by the Schwarz lemma, we obtain

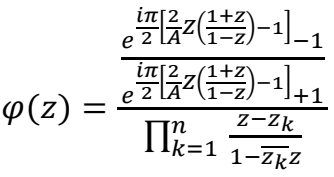

$$
\begin{aligned}
& =\frac{\frac{i \pi}{2}\left(\frac{c_{1}}{A} \frac{4 z}{1-z}+\frac{2 c_{2}}{A}\left(\frac{2 z}{1-z}\right)^{2}+\ldots\right)+\ldots}{\left(2+\frac{i \pi}{2}\left(\frac{c_{1}}{A} \frac{4 z}{1-z}+\frac{2 c_{2}}{A}\left(\frac{2 z}{1-z}\right)^{2}+\ldots\right)+\ldots\right) \prod_{k=1}^{n} \frac{z-z_{k}}{1-\bar{z}_{k} z}}, \\
& \frac{\varphi(z)}{z}=\frac{\frac{i \pi}{2}\left(\frac{c_{1}}{A} \frac{4}{1-z}+\frac{c_{2}}{A} \frac{8 z}{(1-z)^{2}}+\ldots\right)+\ldots}{\left(2+\frac{i \pi}{2}\left(\frac{c_{1}}{A} \frac{4 z}{1-z}+\frac{2 c_{2}}{A}\left(\frac{2 z}{1-z}\right)^{2}+\ldots\right)+\ldots\right) \prod_{k=1}^{n} \frac{z-z_{k}}{1-\overline{z_{k}} z}}
\end{aligned}
$$

and

$$
\left|\varphi^{\prime}(0)\right|=\frac{\pi\left|c_{1}\right|}{A \prod_{k=1}^{n}\left|z_{k}\right|} \leq 1 .
$$

Since $\left|c_{1}\right|=\left|Z^{\prime}(1)\right|$ and $z_{k}=\frac{s_{k}-1}{s_{k}+1}$, we take

$$
\left|Z^{\prime}(1)\right| \leq \frac{A}{\pi} \prod_{k=1}^{n}\left|\frac{s_{k}-1}{s_{k}+1}\right| .
$$

This result is sharp with the function

$$
Z(s)=\frac{A}{2}\left(1+\frac{2}{i \pi} \ln \left(\frac{1-\frac{s-1}{s+1} \prod_{k=1}^{n} \frac{\frac{s-1}{s+1}-\frac{s_{k}-1}{s_{k}+1}}{1-\frac{\overline{s_{k}-1} s-1}{s_{k}+1 s+1}}}{1+\frac{s-1}{s+1} \prod_{k=1}^{n} \frac{\frac{s-1}{s+1}-\frac{s_{k}-1}{s_{k}+1}}{1-\frac{s_{k}-1}{s_{k}+1}}}\right),\right.
$$

where $s_{1}, s_{2}, \ldots, s_{n}$ are positive real numbers.

Therefore, we obtain the following lemma.

Lemma 1. Let $Z(s)=\frac{A}{2}+c_{1}(s-1)+c_{2}(s-1)^{2}+\ldots$ be a positive real function with $0<\Re Z(s) \leq A$ for $\Re s \geq 0$. Suppose that $s_{1}, s_{2}, \ldots, s_{n}$ are points in the right half of the s-plane with $Z\left(s_{k}\right)=\frac{A}{2}, k=1,2, \ldots, n$. In this case, we have the inequality

$$
\left|Z^{\prime}(1)\right| \leq \frac{A}{\pi} \prod_{k=1}^{n}\left|\frac{s_{k}-1}{s_{k}+1}\right| .
$$

The inequality (1) is sharp, with equality for the function 


$$
Z(s)=\frac{A}{2}\left(1+\frac{2}{i \pi} \ln \left(\frac{1-\frac{s-1}{s+1} \prod_{k=1}^{n} \frac{\frac{s-1}{s+1}-\frac{s_{k}-1}{s_{k}+1}}{1-\frac{s_{k}-1}{s_{k}+1} s^{+1}}}{1+\frac{s-1}{s+1} \prod_{k=1}^{n} \frac{\frac{s-1}{s+1}-\frac{s_{k}-1}{s_{k}+1}}{1-\frac{s_{k}-1}{s-1}}}\right)\right) .
$$

A significant result of the Schwarz lemma is given by Osserman as follows [13]:

Let $f: U \rightarrow U$ be analytic. Suppose that $f(0)=0$. Further suppose that there is a $z_{0} \in \partial U$ so that $f$ extends continuously to $z_{0},\left|f\left(z_{0}\right)\right|=1$ and $f^{\prime}\left(z_{0}\right)$ exists. Then

$$
\left|f^{\prime}\left(z_{0}\right)\right| \geq \frac{2}{1+\left|f^{\prime}(0)\right|} .
$$

Inequality (2) is sharp, with equality possible for each value of $\left|f^{\prime}(0)\right|$.

Inequality (2) and its generalizations have important applications in geometric theory of functions and they are still hot topics in the mathematics literature [14]-[22].

It is clear that the generic extremal function obtained in Lemma 1 takes different forms for different values of $n$ parameter. As an exemplary application, the DPIFs for $n=1,2,3$, and 4 are given as follows:

$$
\begin{gathered}
Z_{n=1}(s)=\frac{A}{2}\left[1+\frac{2}{i \pi} \ln \left(\frac{s\left(s_{1}+1\right)}{s^{2}+s_{1}}\right)\right] \\
Z_{n=2}(s)=\frac{A}{2}\left[1+\frac{2}{i \pi} \ln \left(\frac{\left(s_{1}+s_{2}+1\right) s^{2}+s_{1} s_{2}}{s^{3}+\left(s_{1}+s_{2}+s_{1} s_{2}\right) s}\right)\right] \\
Z_{n=3}(s)=\frac{A}{2}+\frac{A}{i \pi} \ln \left(\frac{\left(s_{1}+s_{2}+s_{3}+1\right) s^{3}+\left(s_{1} s_{2}+s_{1} s_{3}+s_{2} s_{3}+s_{1} s_{2} s_{3}\right) s}{s^{4}+\left(s_{1}+s_{2}+s_{3}+s_{1} s_{2}+s_{1} s_{3}+s_{2} s_{3}\right) s^{2}+s_{1} s_{2} s_{3}}\right) \\
Z_{n=4}(s)=\frac{A}{2}\left[1+\frac{1}{i \pi} \ln \left(\frac{\alpha_{1} s^{4}+\alpha_{2} s^{2}+\alpha_{3}}{s^{5}+\alpha_{4} s^{3}+\alpha_{5} s}\right)\right],
\end{gathered}
$$

where

$$
\begin{gathered}
\alpha_{1}=s_{1}+s_{2}+s_{3}+s_{4}+1 \\
\alpha_{2}=s_{1} s_{2}+s_{1} s_{3}+s_{1} s_{4}+s_{2} s_{3}+s_{2} s_{4}+s_{3} s_{4} \\
+s_{1} s_{2} s_{3}+s_{1} s_{2} s_{4}+s_{1} s_{3} s_{4}+s_{2} s_{3} s_{4} \\
\alpha_{3}=s_{1} s_{2} s_{3} s_{4} \\
\alpha_{4}=s_{1}+s_{2}+s_{3}+s_{4}+s_{1} s_{2}+s_{1} s_{3}+s_{1} s_{4}+s_{2} s_{3}+ \\
s_{2} s_{4}+s_{3} s_{4} \\
\alpha_{5}=s_{1} s_{2} s_{3}+s_{1} s_{2} s_{4}+s_{1} s_{3} s_{4}+s_{2} s_{3} s_{4}+s_{1} s_{2} s_{3} s_{4}
\end{gathered}
$$

The corresponding frequency response graphics for the obtained DPIFs are presented in Figs. 1 through 4, respectively. According to figures, it can be seen that the number of the notches changes depending on the $n$ parameter in the generic DPIF. In all figures, the filters exhibit a spiky structure for low frequency values and highpass filter structure for higher values of $w$.

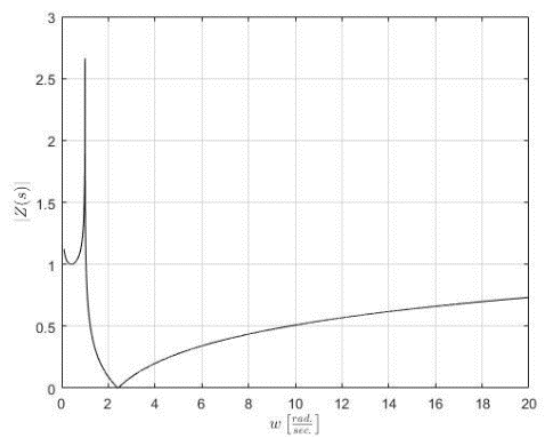

Figure 1. $n=1$

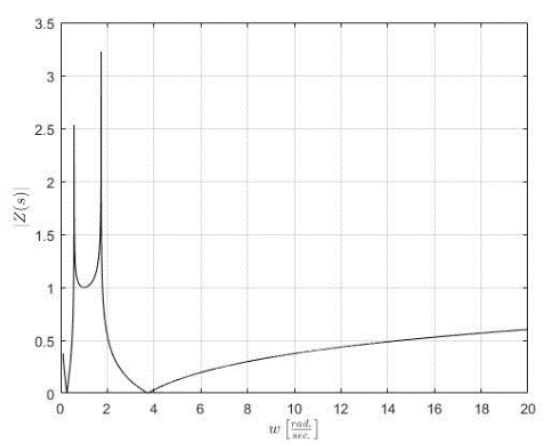

Figure 2. $n=2$

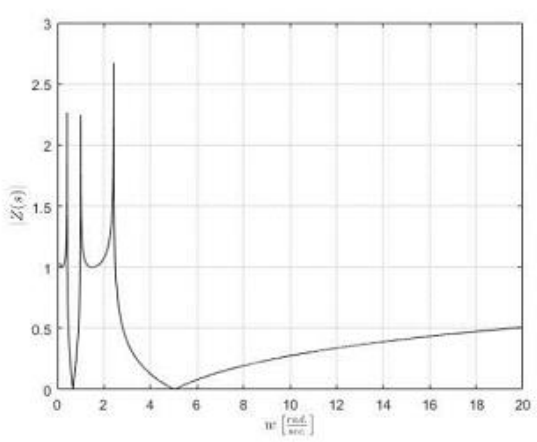

Figure $3 \cdot n=3$

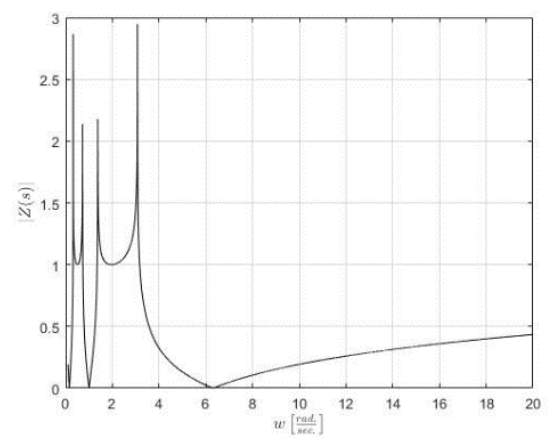

Figure 4. $n=4$

\section{Main Results}

In this section, the modulus of the derivative of the $Z(s)$ function at the zero point will be examined.

Theorem 1 Let $Z(s)=\frac{A}{2}+c_{1}(s-1)+c_{2}(s-1)^{2}+\ldots$ be a PRF with $0<\Re Z(s) \leq A$ for $\Re s \geq 0$ that is also analytic at the point $s=0$ of the imaginary axis with $Z(0)=A$. Suppose that 
$s_{1}, s_{2}, \ldots, s_{n}$ are points in the right half of the s-plane with $Z\left(s_{k}\right)$ $=\frac{A}{2}, k=1,2, \ldots, n$. Then

$$
\left|Z^{\prime}(0)\right| \geq \frac{2 A}{\pi}\left(1+\sum_{k=1}^{n} \frac{\mathfrak{R} s_{k}}{\left|s_{k}\right|^{2}}\right.
$$

$$
\left.+\frac{2\left(A\left(\prod_{k=1}^{n}\left|\frac{s_{k}-1}{s_{k}+1}\right|\right)-\pi\left|c_{1}\right|\right)^{2}}{A^{2}\left(\prod_{k=1}^{n}\left|\frac{s_{k}-1}{s_{k}+1}\right|\right)^{2}-\pi^{2}\left|c_{1}\right|^{2}+A \pi \prod_{k=1}^{n}\left|\frac{s_{k}-1}{s_{k}+1}\right|\left|2 c_{2}+c_{1}\left(1+\sum_{k=1}^{n} \frac{4 \Re s_{k}}{\left|s_{k}\right|^{2}+2 i s_{s_{k}-1}}\right)\right|}\right) .
$$

The inequality (3) is sharp with the extremal function

$$
Z(s)=\frac{A}{2}\left(1+\frac{2}{i \pi} \ln \left(\frac{1-i\left(\frac{s-1}{s+1}\right)^{2} \prod_{k=1}^{n} \frac{\frac{s-1}{s+1}-\frac{s_{k}-1}{s_{k}+1}}{1-\frac{s_{k}-1}{s_{k}+1}}}{1+i\left(\frac{s-1}{s+1}\right)^{2} \prod_{k=1}^{n} \frac{\frac{s-1}{s+1}-\frac{s_{k}-1}{s_{k}+1}}{1-\frac{s_{k}-1}{s_{k}+1 s+1}}}\right),\right.
$$

where $s_{1}, s_{2}, \ldots, s_{n}$ are positive real numbers.

Proof. Let $z_{1}, z_{2}, \ldots, z_{n}$ be zeros of the function $f(z)$ in $U$ different from $z=0$. The Blaschke product

$$
B_{0}(z)=z \prod_{k=1}^{n} \frac{z-z_{k}}{1-\overline{z_{k}} z}
$$

is analytic function in $U$ and $\left|B_{0}(z)\right|<1$ for $z \in U$. By the maximum principle implies that for each $z \in U$ we have the inequality $|f(z)| \leq\left|B_{0}(z)\right|$. Therefore, the absolute value of the function

$$
\phi(z)=\frac{f(z)}{B_{0}(z)}
$$

is analytic in $U$ is bounded by 1 in $U$. Namely, $|\phi(z)| \leq 1$ for $|z|<1$.

In particular, we have

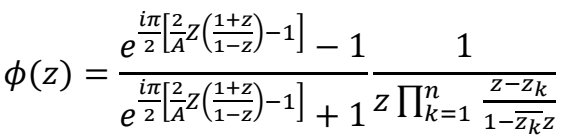

$$
\begin{aligned}
& =\frac{\frac{i \pi}{2}\left(\frac{c_{1}}{A} \frac{4 z}{1-z}+\frac{2 c_{2}}{A}\left(\frac{2 z}{1-z}\right)^{2}+\ldots\right)+\ldots}{\left(2+\frac{i \pi}{2}\left(\frac{c_{1}}{A} \frac{4 z}{1-z}+\frac{2 c_{2}}{A}\left(\frac{2 z}{1-z}\right)^{2}+\ldots\right)+\ldots\right) z \prod_{k=1}^{n} \frac{z-z_{k}}{1-\overline{z_{k}} z}} \\
& =\frac{\frac{i \pi}{2}\left(\frac{c_{1}}{A} \frac{4}{1-z}+\frac{8 c_{2}}{A} \frac{z}{(1-z)^{2}}+\ldots\right)+\ldots}{\left(2+\frac{i \pi}{2}\left(\frac{c_{1}}{A} \frac{4 z}{1-z}+\frac{2 c_{2}}{A}\left(\frac{2 z}{1-z}\right)^{2}+\ldots\right)+\ldots\right) \prod_{k=1}^{n} \frac{z-z_{k}}{1-\overline{z_{k}} z}}, \\
& |\phi(0)|=\frac{\pi\left|c_{1}\right|}{A \prod_{k=1}^{n}\left|z_{k}\right|}
\end{aligned}
$$

and

$$
\left|\phi^{\prime}(0)\right|=\frac{\pi}{A} \frac{\left|2 c_{2}+c_{1}\left(1+\sum_{k=1}^{n} \frac{1-\left|z_{k}\right|^{2}}{z_{k}}\right)\right|}{\prod_{k=1}^{n}\left|z_{k}\right|} .
$$

In addition, it can be seen that

$$
\frac{z_{0} f^{\prime}\left(z_{0}\right)}{f\left(z_{0}\right)}=\left|f^{\prime}\left(z_{0}\right)\right| \geq\left|B_{0}^{\prime}\left(z_{0}\right)\right|=\frac{z_{0} B_{0}^{\prime}\left(z_{0}\right)}{B_{0}\left(z_{0}\right)},-1=z_{0} \in \partial U .
$$

The auxiliary function

$$
\Theta(z)=\frac{\phi(z)-\phi(0)}{1-\overline{\phi(0)} \phi(z)}
$$

is an analytic function in the unit disc $U,|\Theta(z)|<1$ for $z \in U$, $\Theta(0)=0$ and $\left|\Theta\left(z_{0}\right)\right|=1$ for $z_{0}=-1 \in \partial U$. From inequality (2), we obtain

$$
\begin{gathered}
\frac{2}{1+\left|\Theta^{\prime}(0)\right|} \leq\left|\Theta^{\prime}(-1)\right|=\frac{1-|\phi(0)|^{2}}{|1-\overline{\phi(0)} \phi(-1)|^{2}}\left|\phi^{\prime}(-1)\right| \\
\leq \frac{1+|\phi(0)|}{1-|\phi(0)|}\left|\frac{f^{\prime}(-1)}{B_{1}(-1)}-\frac{f(-1) B_{1}^{\prime}(-1)}{B_{1}^{2}(-1)}\right| \\
\quad=\frac{1+|\phi(0)|}{1-|\phi(0)|}\left(\left|f^{\prime}(-1)\right|-\left|B_{1}^{\prime}(-1)\right|\right) .
\end{gathered}
$$

Since

$$
\Theta^{\prime}(z)=\frac{1-|\phi(0)|^{2}}{(1-\overline{\phi(0)} \phi(z))^{2}} \phi^{\prime}(z)
$$

$$
\begin{aligned}
\left|\Theta^{\prime}(0)\right| & =\frac{\left|\phi^{\prime}(0)\right|}{1-|\phi(0)|^{2}}=\frac{\frac{\pi}{A} \frac{\left|2 c_{2}+c_{1}\left(1+\sum_{k=1}^{n} \frac{1-\left|z_{k}\right|^{2}}{z_{k}}\right)\right|}{\prod_{k=1}^{n}\left|z_{k}\right|}}{1-\left(\frac{\pi\left|c_{1}\right|}{A \prod_{k=1}^{n}\left|z_{k}\right|}\right)^{2}} \\
& =A \pi \prod_{k=1}^{n}\left|z_{k}\right| \frac{\left|2 c_{2}+c_{1}\left(1+\sum_{k=1}^{n} \frac{1-\left|z_{k}\right|^{2}}{z_{k}}\right)\right|}{A^{2}\left(\prod_{k=1}^{n}\left|z_{k}\right|\right)^{2}-\pi^{2}\left|c_{1}\right|^{2}}
\end{aligned}
$$

and

$$
\left|B_{1}^{\prime}(-1)\right|=1+\sum_{k=1}^{n} \frac{1-\left|z_{k}\right|^{2}}{\left|1+z_{k}\right|^{2}}
$$

we obtain

$$
\begin{gathered}
\quad \frac{2}{1+A \pi \prod_{k=1}^{n}\left|z_{k}\right| \frac{\left|2 c_{2}+c_{1}\left(1+\sum_{k=1}^{n} \frac{1-\left|z_{k}\right|^{2}}{z_{k}}\right)\right|}{A^{2}\left(\prod_{k=1}^{n}\left|z_{k}\right|\right)^{2}-\pi^{2}\left|c_{1}\right|^{2}}} \\
\leq \frac{1+\frac{\pi\left|c_{1}\right|}{A \prod_{k=1}^{n}\left|z_{k}\right|}}{1-\frac{\pi\left|c_{1}\right|}{A \prod_{k=1}^{n}\left|z_{k}\right|}}\left(\frac{\pi}{2 A}\left|Z^{\prime}(0)\right|-1-\sum_{k=1}^{n} \frac{1-\left|z_{k}\right|^{2}}{\left|1+z_{k}\right|^{2}}\right) \\
=\frac{A \prod_{k=1}^{n}\left|z_{k}\right|+\pi\left|c_{1}\right|}{A \prod_{k=1}^{n}\left|z_{k}\right|-\pi\left|c_{1}\right|}\left(\frac{\pi}{2 A}\left|Z^{\prime}(0)\right|-1-\sum_{k=1}^{n} \frac{1-\left|z_{k}\right|^{2}}{\left|1+z_{k}\right|^{2}}\right), \\
\quad \frac{A^{2}\left(\prod_{k=1}^{n}\left|z_{k}\right|\right)^{2}-\pi^{2}\left|c_{1}\right|^{2}+A \pi \prod_{k=1}^{n}\left|z_{k}\right| \mid 2 c_{2}+c_{1}\left(1+\sum_{k=1}^{n}\left(\frac{1-\left|z_{k}\right|^{2}}{z_{k}}\right)\right)}{2 A \prod_{k=1}^{n}\left|z_{k}\right|+\pi\left|c_{1}\right|}\left(\frac{\pi}{2 A}\left|Z^{\prime}(0)\right|-1-\sum_{k=1}^{n} \frac{1-\left|z_{k}\right|^{2}}{\left|1+z_{k}\right|^{2}}\right)
\end{gathered}
$$

and

$\frac{2\left(A\left(\prod_{k=1}^{n}\left|z_{k}\right|\right)-\pi\left|c_{1}\right|\right)^{2}}{A^{2}\left(\prod_{k=1}^{n}\left|z_{k}\right|\right)^{2}-\pi^{2}\left|c_{1}\right|^{2}+A \pi \prod_{k=1}^{n}\left|z_{k}\right|\left|2 c_{2}+c_{1}\left(1+\sum_{k=1}^{n}\left(\frac{1-\left|z_{k}\right|^{2}}{z_{k}}\right)\right)\right|}$


$\leq \frac{\pi}{2 A}\left|Z^{\prime}(0)\right|-1-\sum_{k=1}^{n} \frac{1-\left|z_{k}\right|^{2}}{\left|1+z_{k}\right|^{2}}$

Thus, for $z_{k}=\frac{s_{k}-1}{s_{k}+1}$, we obtain inequality (3).

To prove the sharpness of the inequality (3), let $Z\left(\frac{1+z}{1-z}\right)=\frac{A}{2}\left(1+\frac{2}{i \pi} \ln \left(\frac{1-i z^{2} \prod_{k=1}^{n} \frac{z-z_{k}}{1-\bar{z}_{k} z}}{1+i z^{2} \prod_{k=1}^{n} \frac{z-z_{k}}{1-\bar{z}_{k} z}}\right)\right)$.

Then we obtain

$$
\begin{gathered}
\frac{2}{(1-z)^{2}} Z^{\prime}\left(\frac{1+z}{1-z}\right) \\
=\frac{A}{i \pi} \frac{-\left(2 i z \prod_{k=1}^{n} \frac{z-z_{k}}{1-\overline{z_{k}} z}+i z^{2} \sum_{k=1}^{n} \frac{1-\left|z_{k}\right|^{2}}{\left(1-\overline{z_{k}}\right)\left(z-z_{k}\right)} \prod_{k=1}^{n} \frac{z-z_{k}}{1-\overline{z_{k}} z}\right) c}{\left(1+i z^{2} \prod_{k=1}^{n} \frac{z-z_{k}}{1-\bar{z}_{k} z}\right)\left(1-i z^{2} \prod_{k=1}^{n} \frac{z-z_{k}}{1-\bar{z}_{k} z}\right)} \\
-\frac{A}{i \pi} \frac{\left(2 i z \prod_{k=1}^{n} \frac{z-z_{k}}{1-\overline{z_{k}} z}+i z^{2} \prod_{k=1}^{n} \frac{z-z_{k}}{1-\overline{z_{k}} z} \sum_{k=1}^{n} \frac{1-\left|z_{k}\right|^{2}}{\left(1-\overline{z_{k}} z\right)\left(z-z_{k}\right)}\right) D}{\left(1+i z^{2} \prod_{k=1}^{n} \frac{z-z_{k}}{1-\overline{z_{k}} z}\right)\left(1-i z^{2} \prod_{k=1}^{n} \frac{z-z_{k}}{1-\overline{z_{k}} z}\right)},
\end{gathered}
$$

where

$$
C=\left(1+i z^{2} \prod_{k=1}^{n} \frac{z-z_{k}}{1-\overline{z_{k}} z}\right)
$$

and

$$
D=\left(1-i z^{2} \prod_{k=1}^{n} \frac{z-z_{k}}{1-\overline{z_{k}} z}\right)
$$
take

For $z=-1$ and since $z_{1}, \ldots, z_{n}$ are positive real numbers, we

$$
\left|Z^{\prime}(0)\right|=\frac{2 A}{\pi}\left(2+\sum_{k=1}^{n} \frac{1-z_{k}}{1+z_{k}}\right)
$$

Also, since $z_{k}=\frac{s_{k}-1}{s_{k}+1}$, we obtain

$$
\left|Z^{\prime}(0)\right|=\frac{2 A}{\pi}\left(2+\sum_{k=1}^{n} \frac{1-\frac{s_{k}-1}{s_{k}+1}}{1+\frac{s_{k}-1}{s_{k}+1}}\right)=\frac{2 A}{\pi}\left(2+\sum_{k=1}^{n} \frac{1}{s_{k}}\right) .
$$

Moreover, since $\left|c_{1}\right|=0$ and $\left|c_{2}\right|=\frac{A}{2 \pi} \prod_{k=1}^{n}\left|z_{k}\right|=$ $\frac{A}{2 \pi} \prod_{k=1}^{n}\left|\frac{s_{k}-1}{s_{k}+1}\right|$, inequality (3) holds.

A similar analysis to the one made for Lemma 1 can also considered for the generic DPIF obtained in Theorem 1. Again, for $n=1$ and $n=2$, the DPIFs are given as

$Z_{n=1}(s)=\frac{A}{2}$

$+\frac{A}{i \pi} \ln \left(\frac{(1-i)\left(s^{3}+s+2 s s_{1}\right)+(1+i)\left(2 s^{2}+s+s^{2} s_{1}+s_{1}\right)}{(1+i)\left(s^{3}+s+2 s s_{1}\right)+(1-i)\left(2 s^{2}+s+s^{2} s_{1}+s_{1}\right)}\right)$

and

$$
Z_{n=2}(s)=\frac{A}{2}\left[1+\frac{2}{i \pi} \ln \left(\frac{\alpha(1-i)+\beta(1+i)}{\alpha(1+i)+\beta(1-i)}\right)\right]
$$

where

$$
\begin{aligned}
& \alpha=\left(s^{4}+\left(s_{1} s_{2}+2 s_{1}+2 s_{2}+1\right) s^{2}+s_{1} s_{2}\right) \\
& \beta=\left(\left(s_{1}+s_{2}+1\right) s^{3}+\left(s_{1}+s_{2}+2 s_{1} s_{2}\right) s\right)
\end{aligned}
$$

Since the DPIFs for $n=3$ and $n=4$ are highly complex and do not make a significant contribution at this point, they are not included in this section. However, their frequency characteristics are presented in Fig. 7 and 8, respectively. As in Lemma 1, multinotch filter structures are observed for Theorem 1. However, all the DPIFs obtained in Theorem 1 show low-pass filter characteristics in contrary to Lemma 1 . The results are shown in Figs. 5 through 8 for $n=1,2,3$ and 4, respectively.

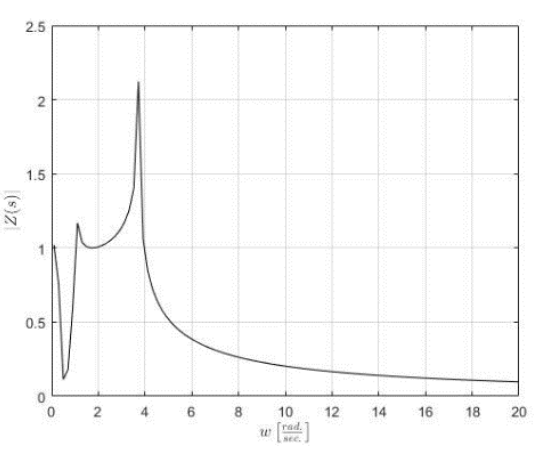

Figure 5. $n=1$

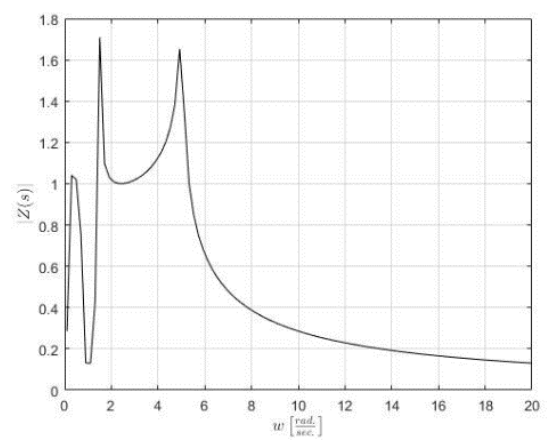

Figure 6. $n=2$

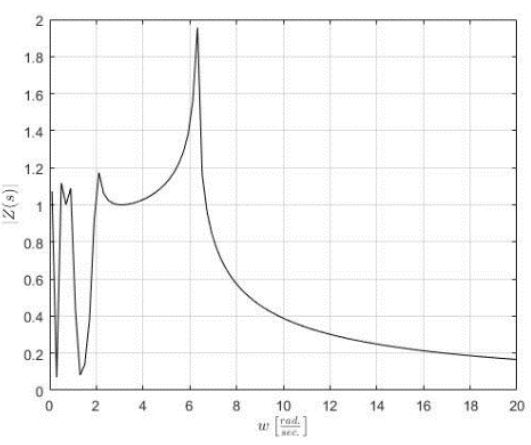

Figure 7. $n=3$ 


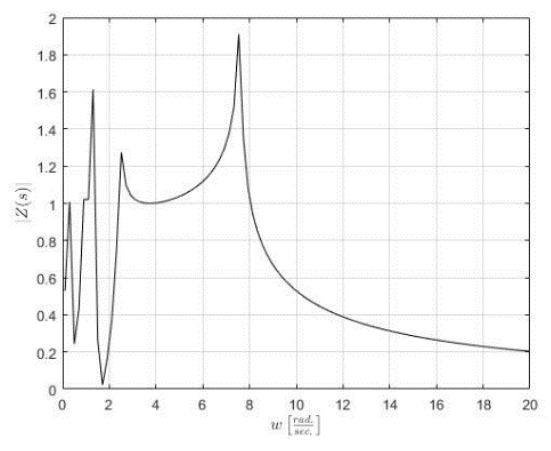

Figure 8. $n=4$

\section{Conclusions}

In this paper, boundary version of the Carathéodory's inequality has been evaluated for driving point impedance functions. Accordingly, a lemma and a theorem have been presented by assuming that the DPIF, $Z(s)$, has the structure of $Z(s)=\frac{A}{2}+c_{1}(s-1)+c_{2}(s-1)^{2}+\ldots$ Two inequalities have been obtained for $\left|Z^{\prime}(1)\right|$ and $\left|Z^{\prime}(0)\right|$ in the presented lemma and theorem, respectively, and two corresponding extremal functions have been derived by performing sharpness analysis. According to frequency analysis results of the obtained extremal functions, it can be said that design of multi-notch filters with different number of spikes is possible by performing the presented analysis in this study.

\section{References}

[1] Akkaya, R., Endiz, M. S. (2020). Yarı empedans kaynaklı inverter Devresinin Performans analizi. European Journal of Science and Technology (EJOSAT), Special Issue, 13-20. https://doi.org/10.31590/ejosat.801852

[2] Örnek, B. N., Düzenli, T. (2018). On boundary analysis for derivative of driving point impedance functions and its circuit applications. IET Circuits, Devices \& Systems, 13(2), 145-152. https://doi.org/10.1049/iet-cds.2018.5123

[3] Örnek, B. N., Düzenli, T. (2018). Boundary Analysis for the derivative of driving point impedance functions. IEEE Transactions on Circuits and Systems II: Express Briefs, 65(9), 1149-1153. https://doi.org/10.1109/tcsii.2018.2809539

[4] Tavazoei, M. S. (2018). Passively realisable impedance functions by using two fractional elements and some resistors. IET Circuits, Devices \& Systems, 12(3), 280-285. https://doi.org/10.1049/iet-cds.2017.0342

[5] Mukhtar, F., Kuznetsov, Y., Russer, P. (2011). Network modelling with Brune's Synthesis. Advances in Radio Science, 9, 91-94. https://doi.org/10.5194/ars-9-91-2011

[6] Wunsch, A. D., Sheng-Pin Hu. (1996). A closed-form expression for the driving-point impedance of the small inverted L Antenna. IEEE Transactions on Antennas and Propagation, 44(2), 236-242. https://doi.org/10.1109/8.481653

[7] Reza, F. M. (1962). A bound for the derivative of positive real functions. SIAM Review, 4(1), 40-42. https://doi.org/10.1137/1004005
[8] Richards, P. I. (1947). A special class of functions with positive real part in a half-plane. Duke Mathematical Journal, 14(3), 777789. https://doi.org/10.1215/s0012-7094-47-01461-0

[9] Dineen, S. (2016). Schwarz lemma. Dover Publications Inc.

[10] Kresin, G., Maz'Ya, V., Shaposhnikova, T. (2007). Sharp realpart theorems: A unified approach. Springer.

[11] Örnek, B. N. (2015). Carathéodory's inequality on the boundary. The Pure and Applied Mathematics, 22(2), 169-178. https://doi.org/10.7468/jksmeb.2015.22.2.169

[12] Ornek, B. N. (2016). The caratheodory inequality on the boundary for holomorphic functions in the unit disc. Journal of Mathematical Physics, Analysis, Geometry, 12(4), 287-301. https://doi.org/10.15407/mag12.04.287

[13] Osserman, R. (2000). A Sharp schwarz inequality on the boundary. Proceedings of the American Mathematical Society, 128(12), 3513-3517. https://doi.org/10.1090/s0002-9939-00$\underline{05463-0}$

[14] Mercer, P. R. (1997). Sharpened versions of the Schwarz lemma. Journal of Mathematical Analysis and Applications, 205(2), 508-511. https://doi.org/10.1006/jmaa.1997.5217

[15] Mercer, P. R. (2018). Boundary Schwarz inequalities arising from Rogosinski's lemma. Journal of Classical Analysis, (2), 9397. https://doi.org/10.7153/jca-2018-12-08

[16] Mercer, P. R. (2018). An improved Schwarz lemma at the boundary. Open Mathematics, 16(1), 1140-1144. https://doi.org/10.1515/math-2018-0096

[17] Dubinin, V. N. (2004). The Schwarz inequality on the boundary for functions regular in the disk. Journal of Mathematical Sciences, 122(6), 3623-3629. https://doi.org/10.1023/b:joth.0000035237.43977.39

[18] Mateljevic, M. (2018). 'Rigidity of holomorphic mappings \& Schwarz and Jack lemma', https://doi.org/10.13140/RG.2.2.34140.90249.

[19] Azeroğlu, T. A., Örnek, B. N. (2012). A refined Schwarz inequality on the boundary. Complex Variables and Elliptic Equations, 58(4), 571-577. https://doi.org/10.1080/17476933.2012.718338

[20] Harold P. Boas. (2010). Julius and julia: Mastering the art of the schwarz lemma. The American Mathematical Monthly, 117(9), 770-785. https://doi.org/10.4169/000298910x521643

[21] Örnek, B. N., Düzenli, T. (2021). Rogosinski Lemması ile ilgili Süren Nokta Empedans Fonksiyonları için Carathéodory Eşitsizliği. Dicle Üniversitesi Mühendislik Fakültesi (DÜMF) Mühendislik Dergisi, 12(1), 61-68.

https://doi.org/10.24012/dumf.860229

[22] Örnek, B. N., Düzenli, T. (2021). Sharpened forms for driving point impedance functions at boundary of right half plane. Mühendislik Bilimleri ve Tasarım Dergisi, 9(4), 1093-1105. https://doi.org/10.21923/jesd.945359 